\title{
Crack growth induced delamination on steel members reinforced by prestressed composite patch
}

\author{
P. COLOMBI ${ }^{1}$, A. BASSETTI ${ }^{2}$ and A. NUSSBAUMER ${ }^{2}$ \\ ${ }^{1}$ Department of Structural Engineering, Milan Technical University, Milan, Italy, ${ }^{2}$ Institute of Steel Construction, Swiss Federal Institute of Technology, \\ EPFL, Lausanne, Switzerland
}

Received in final form 6 August 2002

\begin{abstract}
A B S TRACT Prestressed composite patch bonded on cracked steel section is a promising technique to reinforce cracked details or to prevent fatigue cracking on steel structural elements. It introduces compressive stresses that produce a crack closure effect. Moreover, it modifies the crack geometry by bridging the crack faces and so reduces the stress intensity range at the crack tip. Fatigue tests were performed on notched steel plate reinforced by CFRP strips as a step toward the validation of crack patching for fatigue life extension of riveted steel bridges. A crack growth induced debonded region in the adhesive-plate interface was observed using an optical technique. Moreover, the size of the debonded region significantly influences the efficiency of the crack repair. Debond crack total strain energy release rate is computed by the modified virtual crack closure technique (MVCCT). A parametric analysis is performed to investigate the influence of some design parameters such as the composite patch Young's modulus, the adhesive thickness and the pretension level on the adhesive-plate interface debond.
\end{abstract}

Keywords composite patch reinforcement; debond crack; strain energy release rate.

\section{INTRODUCTION}

Work on reinforcement of cracked aluminium structures by composite patches started in the seventies and today is a standard procedure in aircraft industry. ${ }^{1}$ Other applications on structural elements subjected to extreme actions (high fatigue loads, high temperature ranges and exposure to aggressive agents) in the automotive and aeronautical industry showed that it is possible to produce high strength assemblies using composite materials bonded to thin metallic elements. ${ }^{2}$ At the beginning of the nineties it was shown that the properties of carbon fibre laminates (CFRP) could be exploited also in civil engineering applications and the reinforcement of concrete bridges with CFRP-laminates was achieved. ${ }^{3}$ This technical realisation showed that composites bonded with epoxy resins are a reliable solution for strengthening of bridges. It was also shown that the very high tensile strength of

Correspondence: P. Colombi, Department of Structural Engineering, Milan Technical University, Piazza L. da Vinci, 32,20133 Milan, Italy. E-mail: colombi@stru.polimi.it composite materials could be exploited in order to prestress the CFRP-laminates. ${ }^{4}$ More recently, attempts were made to reinforce metallic structures in civil engineering with composite materials in order to increase the load carrying capacity of the steel bridge sections. ${ }^{5}$ Finally, CFRP patch, eventually prestressed prior to bonding, was proposed. ${ }^{6-11}$ as an innovative reinforcement methodology for steel structural elements damaged by fatigue. CFRP-laminates have physical and mechanical properties that are particularly interesting for reinforcement of fatigue damaged steel elements. The high fatigue resistance of CFRP avoids crack propagation from the cracked steel section into the patch. The high stiffness of CFRP reduces the stress range in the cracked steel section and promotes crack bridging. The high tensile strength of CFRP also enables a pretension to be applied to composite strips so as to promote crack closure in thicker steel sections. Finally, the low self-weight of CFRP plates limits the dead load increment and simplifies the strengthening operations. The effectiveness of this technique was verified by fatigue tests on notched steel plate reinforced by CFRP strips. Several fatigue tests on 
cross-girders of riveted steel bridges reinforced by CFRP strips were also performed in order to show the applicability to bridge reinforcement. ${ }^{6-11}$ Fatigue tests showed that the application of a pretension to CFRP patch prior to bonding produces a significant increment of the remaining fatigue life. All the documented applications show the technical feasibility of civil engineering structures being strengthened and rehabilitated by using composite materials.

The high fatigue resistance of CFRP laminates prevents fatigue crack propagation in the composite patch but a debonded region is created between the steel plate and the reinforcement. This debond crack may propagate in the adhesive-plate or adhesive-patch interface but it is expected that the debond at the adhesive-plate interface will more likely initiate and grow due to a high stress concentration in the cracked plate. The evaluation of mode I and mode II strain energy release rates ${ }^{12,13}$ was performed in the literature in order to provide a fracture criterion for interfacial cracks. It is well known that the bi-material interface crack always induces both opening and shearing mode behaviour for single mode loading. ${ }^{14}$ The stress field possesses a physically inadmissible oscillatory character that is confined to a small stress region near the end of the crack. The modified virtual crack closure technique (MVCCT) is an expedient method to calculate the strain energy release rate, G. ${ }^{15}$ This technique allows calculation of the strain energy release rate through a single analysis. The concept is to calculate the strain energy release per unit area for the extension of the crack over a short distance, $\Delta a$. It is well known that the strain energy release rates for mode I, $G_{\mathrm{I}}$, and mode II, $G_{\mathrm{II}}$, separately are theoretically nonexistent ${ }^{14}$ since they are not defined as $\Delta a$ goes to zero. However, for finite crack extension, $\Delta a$, the individual strain energy release rates exist and could be used ${ }^{16}$ to study delamination crack growth. Alternatively, the total strain energy release rate, $G$, has been used as a fracture parameter for interfacial crack propagation. ${ }^{17}$

In the present paper reference is made to notched steel plate fatigue tests. ${ }^{6-11}$ In previous publications, ${ }^{6-11}$ the stress intensity factor in the cracked plate was computed, but no attempts were made to compute the debond strain energy release rate $G$. Results showed that the size of the debonded region significantly influences the efficiency of the crack repair. The goal of this paper is then first to evaluate the $G$ distribution along the crack growth induced debond front and second to study the influence of some design parameters such as the composite patch Young's modulus, the adhesive thickness and the pretension level on the adhesive-plate interface debond. To this end a suitable two-dimensional finite element model based on the three-layer technique ${ }^{13}$ is realised in order to compute debond crack strain energy release rate by the MVCCT.

\section{REINFORCEMENT OF STEEL MEMBERS BY PRESTRESSED CFRP STRIPS}

The idea ${ }^{6-11}$ was to reinforce fatigue damaged steel members by prestressed CFRP strips. The effectiveness of CFRP patches to reduce or to arrest crack propagation was investigated by fatigue tests on notched steel plate (Fig. 1).

The central notch consists in a hole and two initial cracks produced by electroerosion. Hole diameter and plate thickness are representative of rivet holes and plates thickness used in riveted members since the long-term objective of the research is to show the applicability of such a reinforcement technique to riveted steel bridges. The notched steel plates are reinforced on both sides with two CFRP-strips. The material properties and dimensions of the specimen are reported in Table 1.

The application of composite patches to steel plate does not produce a significant reduction of the stress levels since the stiffness of the steel plate is much larger than the composite strips. Moreover, the application of a large number of composite strips is not possible from both the economical and practical point of view. In order to increase the effectiveness of the patch reinforcement, the CFRP strips must then be prestressed. ${ }^{6-11}$ Prestressing of the CFRP strips introduces compressive stresses that

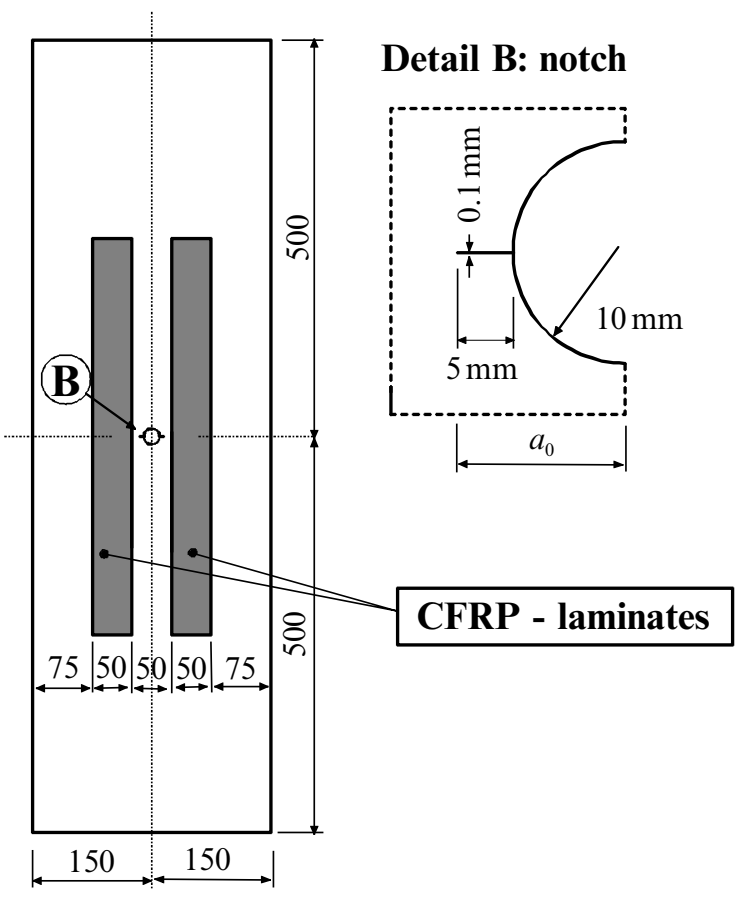

Fig. 1 Test specimen. 
Table 1 Material properties and dimension of the notched steel plate reinforcement

\begin{tabular}{lccll}
\hline Layer & $\begin{array}{l}\text { Length } \\
(\mathrm{mm})\end{array}$ & $\begin{array}{l}\text { Width } \\
(\mathrm{mm})\end{array}$ & $\begin{array}{l}\text { Thickness } \\
(\mathrm{mm})\end{array}$ & $\begin{array}{l}\text { Material } \\
\text { properties }\end{array}$ \\
\hline Steel plate & 1000 & 300 & 10 & $E_{\mathrm{s}}=210 \mathrm{GPa}, v_{\mathrm{s}}=0.3$ \\
Adhesive & 500 & 50 & 0.3 & $\begin{array}{l}E_{\mathrm{a}}=714.14 \mathrm{MPa}, v_{\mathrm{a}}=0.32 \\
\text { CFRP patch }\end{array}$ \\
500 & 50 & 1.2 & $\begin{array}{l}E_{1}=174 \mathrm{GPa}, E_{2}=9 \mathrm{GPa}, \\
v_{12}=0.28, G_{12}=G_{13}=4.5 \mathrm{GPa}\end{array}$ \\
& & & $G_{23}=4.4 \mathrm{GPa}$ \\
\hline
\end{tabular}

promotes the crack closure effect. ${ }^{18}$ In this paper reference is made to fatigue tests on notched steel plate with a constant amplitude load range $\Delta F=240 \mathrm{kN}$ and a load ratio $F_{\min } / F_{\max }=0.4$. Since the thickness of the adhesive $(0.3 \mathrm{~mm})$ is much less than that of the steel plate $(10 \mathrm{~mm})$ and the composite patch $(1.2 \mathrm{~mm})$, a three-dimensional analysis becomes very expensive. A two-dimensional model is then adopted in connection with the MVCCT to evaluate the debond crack strain energy release rate.

\section{Experimental evidence}

As the crack approaches the interior boundary of the patch, the high stress concentration at the crack tip produces a debond at the plate-adhesive or adhesivepatch interface. From the inspection of the failed specimens, it was concluded that debond was present between the steel plate and the adhesive layer. Debond was investigated $^{6-11}$ using the Optical Speckle Interferometry technique. ${ }^{8,9,19}$ The evolution of the displacement field at the specimen surface is reported in Fig. 2.

Each fringe represents a displacement of $1.3 \mu \mathrm{m}$ in the longitudinal direction. At the beginning of the test (Fig. 2a) no relative displacement is present between the steel plate and the adhesive layer. As the crack in the steel plate approaches the external boundary of the composite patch (Fig. 2b), relative displacements are present between the steel plate and the adhesive layer. Moreover, the deformation level in the composite patch is increased. At the end of the test (Fig. 2c), the fatigue crack is outside the patch and the boundary of the delamination zone is parallel to the crack. The dimensions of the debond zones are deduced by comparing the displacement field obtained by finite element calculations with the experimental one. ${ }^{6-11}$ The results showed that the debond zone between adhesive layer and steel plate is well approximated by an ellipse with an aspect ratio $c / b$ of $1 / 5$ (see Fig. 12). The delamination front is supposed to be ahead of the crack tip at a distance equal to the plastic zone.

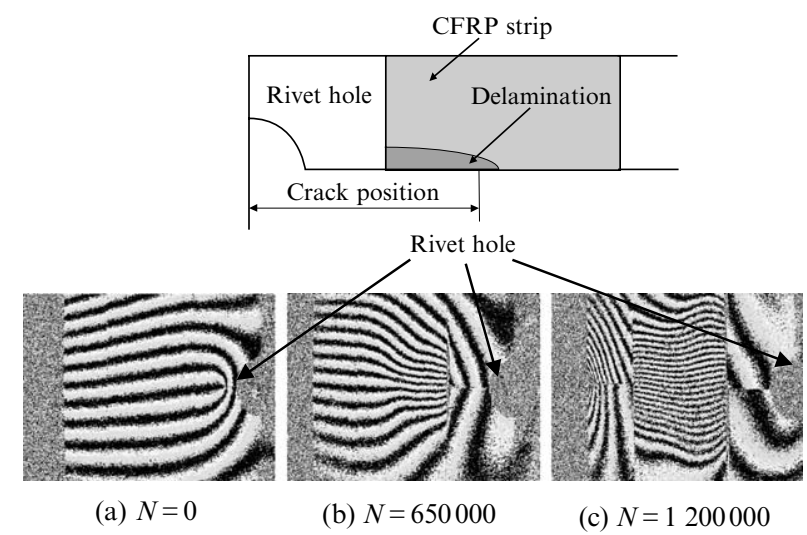

Fig. 2 Displacement field on specimen surface by Optical Speckle Interferometry (a) $N=0$, (b) $N=650000$, and (c) $N=1200000$.

\section{NUMERICAL MODEL}

\section{Three layer technique}

In Ref. [13] the three-layer technique was proposed to model a composite bonded reinforced cracked plate. This technique uses two-dimensional finite element analysis, consisting of three layers, to model the steel plate, adhesive layer and composite patch. It is not required to replace the adhesive layer by shear spring elements (noncontinuum body) ${ }^{12,20}$ since the adhesive layer is modelled as an elastic continuum medium. In this way the characteristics of the adhesive required to model nonlinear material behaviour are also captured directly together with the effects of adhesive rotation. Adhesive rotation effects play a role in the definition of the debonding energy for symmetric patching but they are very important for single patches. ${ }^{13}$ Constraints are used to enforce the compatibility along the plate-adhesive and the adhesive-patch interface based on Mindlin assumptions (Fig. 3).

According to Mindlin plate theory (Fig. 3), all three layers, steel plate, adhesive and composite patch, are assumed to have a linear displacement field along the thickness and they satisfy the relations: ${ }^{13}$ 

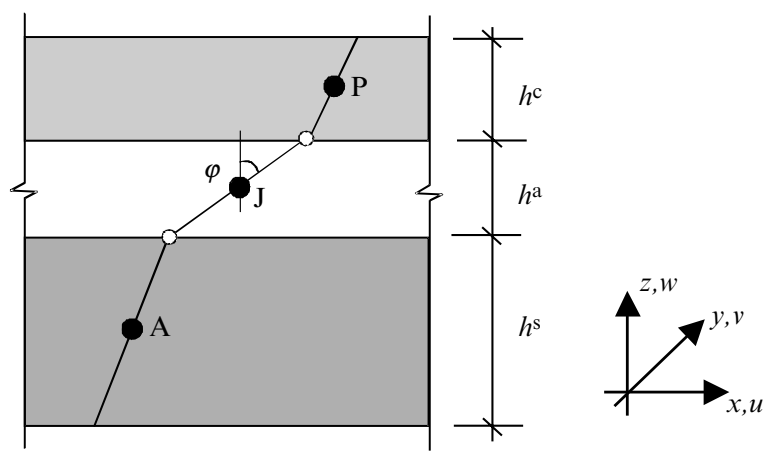

Fig. 3 Modelling of bonded reinforcement and necessary constraints at the interfaces.

$u^{\mathrm{c}}=u_{\mathrm{P}}+\varphi_{y}^{\mathrm{P}} \cdot z^{\mathrm{c}}, \quad u^{\mathrm{a}}=u_{\mathrm{J}}+\varphi_{y}^{\mathrm{J}} \cdot z^{\mathrm{a}}, \quad u^{\mathrm{s}}=u_{\mathrm{A}}+\varphi_{y}^{\mathrm{A}} \cdot z^{\mathrm{s}}$

$v^{\mathrm{c}}=v_{\mathrm{P}}-\varphi_{x}^{\mathrm{P}} \cdot z^{\mathrm{c}}, \quad v^{\mathrm{a}}=v_{\mathrm{J}}-\varphi_{x}^{\mathrm{J}} \cdot z^{\mathrm{a}}, \quad v^{\mathrm{s}}=v_{\mathrm{A}}-\varphi_{x}^{\mathrm{A}} \cdot z^{\mathrm{s}}$

$w^{\mathrm{c}}=w_{\mathrm{P}}, \quad w^{\mathrm{a}}=w_{\mathrm{J}}, \quad w^{\mathrm{s}}=w_{\mathrm{A}}$

where the superscript $\mathrm{s}$, a and $\mathrm{c}$ are used to denote the steel plate, adhesive layer and composite patch, respectively. The co-ordinates $z^{\mathrm{c}}, z^{\mathrm{a}}$ and $z^{\mathrm{s}}$ are measured from the midplane of each layer. Making use of Eq. (1), at the plate-adhesive interface, where the $z$ co-ordinates for the cracked plate and the adhesive layer are equal, the constraint equations reduce to:

$u^{\mathrm{a}}=u^{\mathrm{s}} \Rightarrow u_{\mathrm{J}}-u_{\mathrm{A}}-\varphi_{y}^{\mathrm{J}} \cdot \frac{h^{\mathrm{a}}}{2}-\varphi_{y}^{\mathrm{A}} \cdot \frac{h^{\mathrm{s}}}{2}=0$

$v^{\mathrm{a}}=v^{\mathrm{s}} \Rightarrow v_{\mathrm{J}}-v_{\mathrm{A}}+\varphi_{x}^{\mathrm{J}} \cdot \frac{h^{\mathrm{a}}}{2}+\varphi_{x}^{A} \cdot \frac{b^{\mathrm{s}}}{2}=0$

$w^{\mathrm{a}}=w^{\mathrm{s}}$

and at the adhesive-patch interface, where the $z$ coordinates for the adhesive layer and the composite patch are equal, one has:

$u^{\mathrm{c}}=u^{\mathrm{a}} \Rightarrow u_{\mathrm{P}}-u_{\mathrm{J}}-\varphi_{y}^{\mathrm{P}} \cdot \frac{b^{\mathrm{c}}}{2}-\varphi_{y}^{\mathrm{J}} \cdot \frac{b^{\mathrm{a}}}{2}=0$

$v^{\mathrm{c}}=v^{\mathrm{a}} \Rightarrow v_{\mathrm{P}}-v_{\mathrm{J}}+\varphi_{x}^{\mathrm{P}} \cdot \frac{b^{\mathrm{c}}}{2}+\varphi_{x}^{\mathrm{J}} \cdot \frac{h^{\mathrm{a}}}{2}=0$

$w^{\mathrm{c}}=w^{\mathrm{a}}$

In the three-layer model, the three layer rotations are independent of each other and only use of displacement constraint at the interfaces to enforce geometric compatibility is required. In the debonded region between the steel plate and the adhesive layer, the layers are independent of each other and the constraint equations are no longer valid. Note that due to the symmetry of the reinforcement no overlapping due to translation in the thickness direction is possible.

\section{Strain energy release rate}

The MVCCT $^{15}$ is used to calculate the strain energy release rate along the debond front. This technique

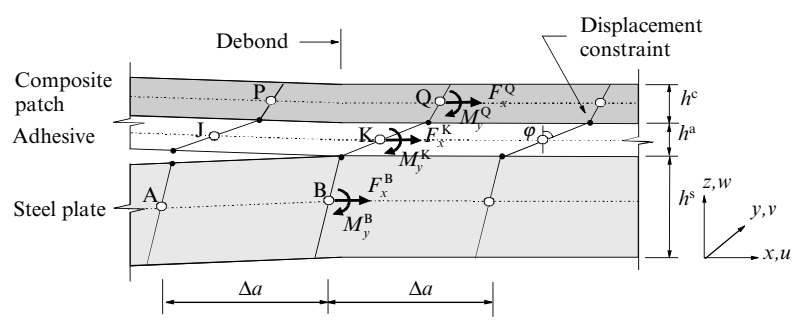

Fig. 4 Schematic three layers model for delaminated plate.

allows calculation of the strain energy release rate in a single analysis. ${ }^{21}$ Consider the schematic three-layer model in Fig. 4.

A four-node Mindlin plate element is used to model the adhesive layer and composite strips. Due to the symmetry, a four-node plane stress element is used to model the steel plate. Delamination is assumed between the steel plate and the adhesive layer as suggested by experimental findings. ${ }^{6-11}$ The concept is to calculate the strain energy release per unit area for the extension of the crack over a short distance $\Delta a$. According to the MVCCT, the generalised forces are evaluated at node $B$. Since the extension $\Delta a$ is very small, the crack opening displacements at $B$ are assumed to be the same as those at $A$. The forces and moments are evaluated from the finite element in the midplane of each layer. They are equal to the static quantities associated with constraints and are computed by summing up the contributions of nodal forces and moments at that node from every element at the node. The strain energy release is evaluated as:

$$
\begin{aligned}
W^{\mathrm{TOT}} & =W_{x}^{\mathrm{BK}}+W_{y}^{\mathrm{BK}}+W_{z}^{\mathrm{BK}} \\
W_{x}^{\mathrm{BK}} & =\frac{1}{2}\left(F_{x}^{\mathrm{B}} \cdot \Delta u\right), \quad W_{y}^{\mathrm{BK}}=\frac{1}{2}\left(F_{y}^{\mathrm{B}} \cdot \Delta v\right), \\
W_{z}^{\mathrm{BK}} & =\frac{1}{2}\left(F_{z}^{\mathrm{B}} \cdot \Delta w\right)
\end{aligned}
$$

where $F_{x}, F_{y}$ and $F_{z}$ are the interface forces in the $x, y$ and $z$ direction, respectively, while $\Delta u, \Delta v$ and $\Delta w$ are the relative displacements between the steel plate and the adhesive layer (Fig. 4). Consider first the contribution to strain energy release in the $x$ direction, $W_{x}^{\mathrm{BK}}$. The constraint forces between the nodes satisfy the following equilibrium equations:

$F_{x}^{\mathrm{B}}+F_{x}^{\mathrm{K}}+F_{x}^{\mathrm{Q}}=0$

$F_{x}^{\mathrm{Q}} \cdot \frac{b^{\mathrm{c}}}{2}+M_{y}^{\mathrm{Q}}=0$

$F_{x}^{\mathrm{Q}} \cdot \frac{h^{\mathrm{a}}}{2}-F_{x}^{\mathrm{B}} \cdot \frac{h^{\mathrm{a}}}{2}+M_{y}^{\mathrm{K}}=0$

$F_{x}^{\mathrm{B}} \cdot \frac{h^{\mathrm{s}}}{2}-M_{y}^{\mathrm{B}}=0$ 
The relative interface displacement in the $x$ direction is given by:

$\Delta u=u_{\mathrm{A}}-u_{\mathrm{J}}+\varphi_{y}^{\mathrm{J}} \cdot \frac{b^{\mathrm{a}}}{2}+\varphi_{y}^{\mathrm{A}} \cdot \frac{b^{\mathrm{s}}}{2}$

The strain energy release contribution is then:

$$
\begin{aligned}
W_{x}^{\mathrm{BK}} & =\frac{1}{2}\left(F_{x}^{\mathrm{B}} \cdot \Delta u\right) \\
& =\frac{1}{2}\left[F_{x}^{\mathrm{B}} u_{\mathrm{A}}-F_{x}^{\mathrm{B}} u_{\mathrm{J}}+F_{x}^{\mathrm{B}} \frac{h^{\mathrm{a}}}{2} \varphi_{y}^{\mathrm{J}}+F_{x}^{\mathrm{B}} \frac{h^{\mathrm{s}}}{2} \varphi_{y}^{\mathrm{A}}\right]
\end{aligned}
$$

Making use of the equilibrium equations (Eq. (5)) and the constraint (nodes $\mathcal{F}$ and $P$ are tied):

$u_{\mathrm{J}}=u_{\mathrm{P}}-\varphi_{y}^{\mathrm{P}} \frac{b^{\mathrm{c}}}{2}-\varphi_{y}^{\mathrm{J}} \frac{b^{\mathrm{a}}}{2}$

the contribution $W_{x}^{\mathrm{BK}}$ to the strain energy release is, after simple manipulations:

$W_{x}^{\mathrm{BK}}=\frac{1}{2}\left[F_{x}^{\mathrm{B}} u_{\mathrm{A}}+M_{y}^{\mathrm{B}} \varphi_{y}^{\mathrm{A}}+F_{x}^{\mathrm{K}} u_{\mathrm{J}}+M_{y}^{\mathrm{K}} \varphi_{y}^{\mathrm{J}}+F_{x}^{\mathrm{Q}} u_{\mathrm{P}}+M_{y}^{\mathrm{Q}} \varphi_{y}^{\mathrm{P}}\right]$

In a similar way the contributions $W_{y}^{\mathrm{BK}}$ and $W_{z}^{\mathrm{BK}}$ are:

$$
\begin{array}{r}
W_{y}^{\mathrm{BK}}=\frac{1}{2}\left[F_{y}^{\mathrm{B}} v_{\mathrm{A}}+M_{x}^{\mathrm{B}} \varphi_{x}^{\mathrm{A}}+F_{y}^{\mathrm{K}} v_{\mathrm{J}}+M_{x}^{\mathrm{K}} \varphi_{y}^{\mathrm{J}}+F_{y}^{\mathrm{Q}} v_{\mathrm{P}}+M_{x}^{\mathrm{Q}} \varphi_{x}^{\mathrm{P}}\right] \\
W_{z}^{\mathrm{BK}}=\frac{1}{2}\left(F_{z}^{\mathrm{B}} w_{\mathrm{A}}+F_{z}^{\mathrm{K}} w_{\mathrm{J}}+F_{z}^{\mathrm{Q}} w_{\mathrm{P}}\right)
\end{array}
$$

The total energy release is then computed by Eq. (4) as:

$W^{\mathrm{TOT}}=\frac{1}{2} \sum_{i}^{5} F_{i}^{\mathrm{s}} u_{i}^{\mathrm{s}}+F_{i}^{\mathrm{a}} u_{i}^{\mathrm{a}}+F_{i}^{\mathrm{c}} u_{i}^{\mathrm{c}}$

where $i$ represents degree of freedom and $F_{i}^{\mathrm{s}}-u_{i}^{\mathrm{s}}, F_{i}^{\mathrm{a}}-u_{i}^{\mathrm{a}}$ and $F_{i}^{\mathrm{c}}-u_{i}^{\mathrm{c}}$ are generalised constraint forces and displacements at the steel plate, adhesive layer and composite patch, respectively. The associated area for the above energy is $A=\Delta a \cdot l$ where $l$ is the element depth in Fig. 4. Thus, the strain energy release rate, $G$, at the delamination front is obtained as:

$G=\frac{W^{\mathrm{TOT}}}{A}$

The accuracy of such a calculation depends on the finite element mesh at the crack front. The procedure was validated $^{22}$ using a typical single-sided patch configuration.

\section{FINITE ELEMENT MODEL}

The commercial finite element code ABAQUS ${ }^{\circledR}$ is used to perform the analyses by the three-layer technique. A schematic view of $1 / 8$ of the finite element model of the reinforced plate geometry is shown in Fig. $5 .^{6-11}$
Since composite strips are located on both sides, the plate is meshed as a continuum medium using standard four-node two-dimensional elements (Fig. 6). In particular, shell elements are used for the adhesive layer and composite patch while plane stress elements are used for the steel plate.

A tensile stress $\sigma_{y, \max }=133 \mathrm{MPa}$ was applied in the $y$ direction to the steel plate. ${ }^{6-11}$ Symmetry boundary conditions are applied to the steel plate node in the $z-y$ plane (displacement in the $x$ direction and rotation along the $y$-axis are then restrained). Again, symmetry boundary conditions are applied to the steel plate, composite strip and adhesive layer in the $x-z$ plane (displacement in the $y$

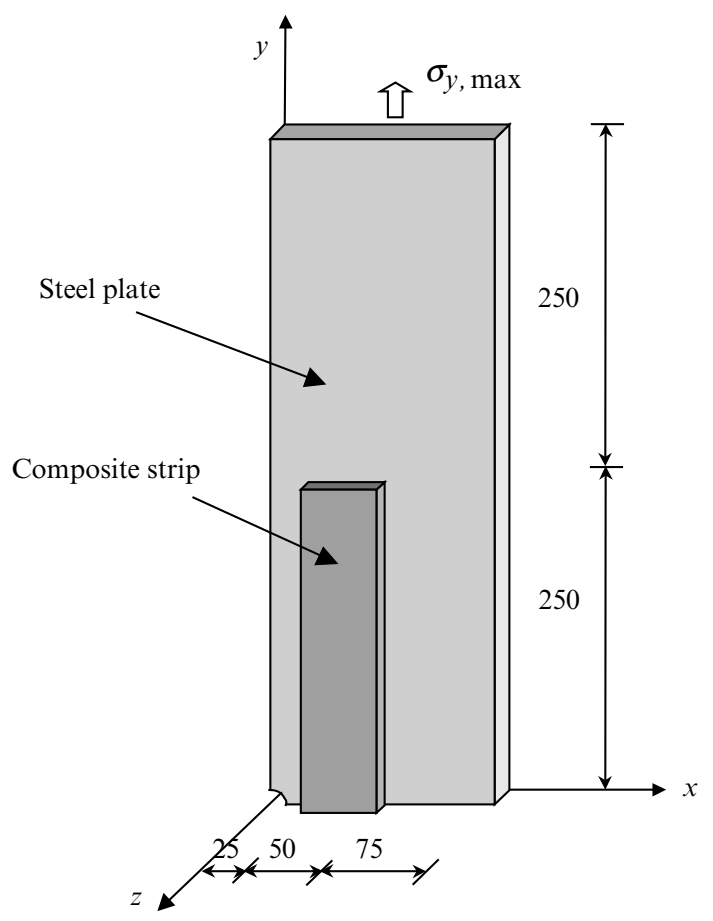

Fig. 5 Crack emanating from a rivet hole reinforced by composite patch.

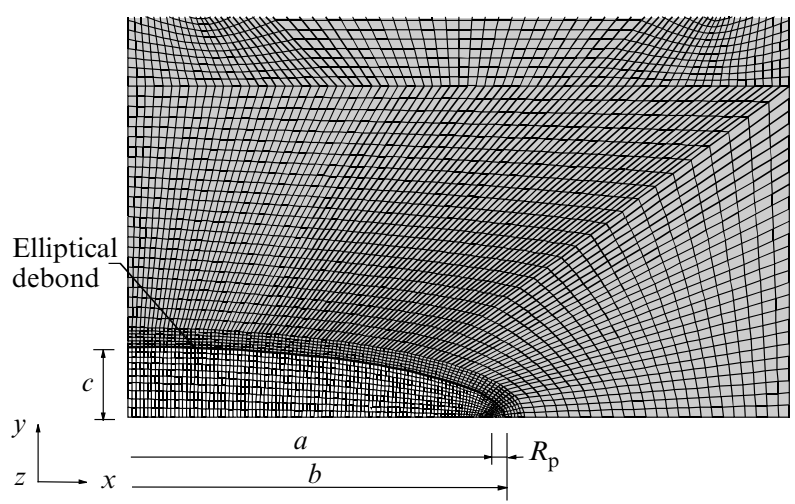

Fig. 6 Detail of the finite element model in the debonding region $(a=50 \mathrm{~mm})$. 
direction and rotation along the $x$-axis are then restrained). Eventually, the prestress of the composite strip is applied by using the initial condition option (stress type) available in ABAQUS ${ }^{\circledR}$. During the prestressed stage, the crack surfaces of the steel plate are in contact.

According to experimental evidence, debond between the adhesive layer and the steel plate is assumed with a semielliptical shape (Fig. 5). The major semiaxis $b$ and the minor semiaxis $c$ are:

$b=a-25+R_{\mathrm{p}}$

$c=b / 5$

where $R_{\mathrm{p}}$ is the size of the plastic zone. It is computed by the Irwin model ${ }^{18}$ as $R_{\mathrm{p}}=1 /(2 \pi) \cdot\left(K / f_{y}\right)^{2}$ where $f_{y}$ is the yield stress. The MVCCT according to the three-layer model is used to compute the debond crack energy release rate. A parametric analysis is then performed in order to investigate the sensitivity of the adhesive-plate interface debond to variations in the composite thickness and Young's modulus in the fibres direction, adhesive thickness, pretension level and the size of the debonded region.

\section{RESULTS AND DISCUSSION}

A refined finite element mesh is required in the debonded region (Fig. 6) in order to achieve a regular behaviour of the $G$ distribution. ${ }^{22}$ The reference parameters are $E_{1}=174 \mathrm{GPa}, b^{\mathrm{c}}=1.2 \mathrm{~mm}, b^{\mathrm{a}}=0.3 \mathrm{~mm}$, an elliptical debonded region with $c / b$ equal to $1 / 5$ and no pretension $\left(\sigma_{\mathrm{p}}=0\right)$ in the composite strips. Reference is made to a crack length $a$ equal to $50 \mathrm{~mm}$ (Fig. 6). Results are presented in Figs 7-9 and 11 as function of the normalised arch length $s$ (Fig. 5). The $G$ distribution corresponding to the reference parameters, which is reported in each figure by cross points, has a relevant maximum value equal to $0.4 \mathrm{~N} / \mathrm{mm}$. The stress $\sigma_{y, \text { max }}$ in the steel plate is equal to $133 \mathrm{MPa}$ and produces a stress intensity factor in the steel plate equal to $1370 \mathrm{~N} / \mathrm{mm}^{3 / 2}$ for a crack length $a=50 \mathrm{~mm} .{ }^{6-11}$ The corresponding strain energy release rate $G$, under the plane stress hypothesis, is equal to $8.9 \mathrm{~N} / \mathrm{mm}$. The debonded strain energy release rate is then much smaller than the corresponding value in the cracked steel plate and it shows that the contribution of debond crack to the strain energy release rate is marginal. Anyway, the extension of the debonded region is of practical importance since it influences the stress intensity factor level in the cracked steel plate. ${ }^{6-11}$

The goal of the following parametric study is to investigate the sensitivity of debond crack strain energy release rate $G$ to some design parameters such as the patch stiffness $\left(E_{1}\right.$ and $\left.b^{\mathrm{c}}\right)$, adhesive thickness $\left(b^{\mathrm{a}}\right)$ and the pretension level $\sigma_{\mathrm{p}}$. A variation of the patch stiffness can be achieved by changing either the patch thickness $b^{\mathrm{c}}$ or the patch Young's modulus $E_{1}$. Results show that the debond crack strain energy release rate is not strongly dependent upon the patch stiffness (Fig. 7).

This is due to the high stiffness of the steel plate compared to that of the CFRP strip. The increment of $E_{1}$ from 100 to $400 \mathrm{GPa}$ produces in fact a reduction of $G$ that is confined to $12 \%$. Note that a corresponding increment of $E_{1}$ produces a $30 \%$ significant decrement of the stress intensity factor in the steel plate. ${ }^{6-11}$ Figure 7 shows that near the steel plate crack tip the strain energy release rate approaches zero. This indicates that the debond crack is unlikely to be ahead of the plate crack. Modifying the patch thickness $b^{c}$ within reasonable bonds does not produce any significant variation in the $G$-values distribution and so the relevant plot is not reported. In fact, the $b^{\mathrm{c}}$ increment produces an increment of the patch shear deformation, which reduces the positive effect connected to stiffness increment. Note that a moderate $16 \%$ decrement of the stress intensity factor in the steel plate was achieved by increasing $b^{\mathrm{c}}$ from 1.0 to $2.0 \mathrm{~mm}^{6-11}$

The adhesive thickness $b^{\mathrm{a}}$ is a very important parameter for the assessment of the effectiveness of the crack reinforcement (Fig. 8).

By increasing $b^{\mathrm{a}}$, the effectiveness is decreased due to shear deformation of the adhesive layer. A $72 \%$ drastic decrement of the $G$-values at the debond crack, as $b^{\mathrm{a}}$ is increased from 0.15 to $1.2 \mathrm{~mm}$, is then achieved due to the reduction of the relative displacements at the interface. Note that a corresponding increment of the adhesive thickness produces a moderate $15 \%$ increment of the stress intensity factor in the steel plate. ${ }^{6-11} \mathrm{~A}$ thinner adhesive layer increases the debond crack energy release rate and a larger debonded region is then expected.

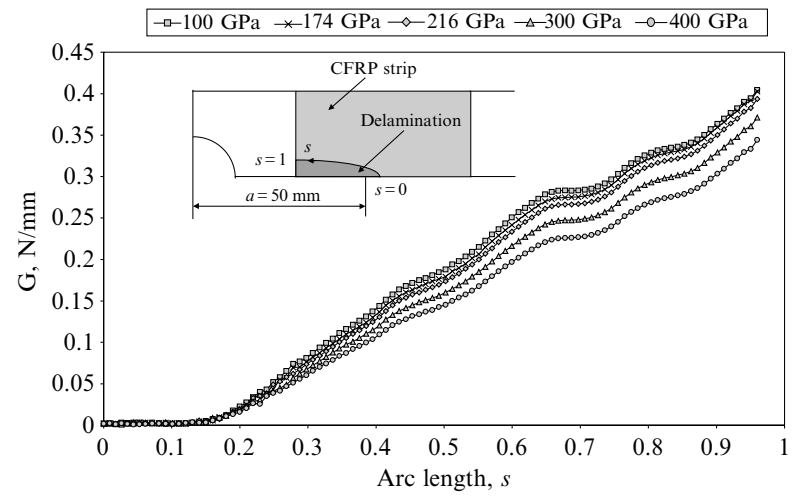

Fig. 7 Influences of composite patch Young's modulus $E_{1}$ on debond crack strain energy release rate. 
The $G$ distribution corresponding to different pretension level $\sigma_{\mathrm{p}}$ is reported in Fig. 9.

A major $87 \%$ reduction of the $G$-values is achieved by increasing the pretension level from 0 to $1000 \mathrm{MPa}$. Numerical results show that the relationship between $\sigma_{\mathrm{p}}$ and the interface relative displacements and forces is linear. This means that the pretension can be considered as a compressive load applied to the steel plate. Under this hypothesis the pretension effect on crack reinforcement is then related to the $G$ distribution for $\sigma_{\mathrm{p}}=0$. Figure 10 shows the debond crack strain energy release rate as function of the pretension level $\sigma_{\mathrm{p}}$ for three different normalised arch lengths $(s=0.3, s=0.6$, $s=0.9$ ).

Pretension reduces from one hand the effort transmitted to the composite strips and from the other hand the crack opening displacements are also decreased. As a result the debond crack strain energy release rate $G$ is drastically reduced. Since the relationship between the relative displacements and forces at the interface is linear, $G$ (see Eqs (12) and (13)) is a quadratic function of $\sigma_{\mathrm{p}}$ as indicated in Fig. 10 by the superimposed curve fitting in Fig. 10 by a second order parabola. Note that prestress

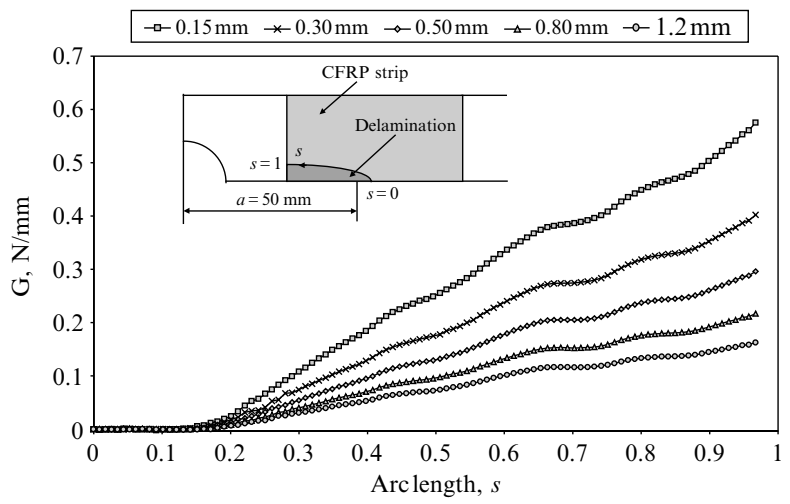

Fig. 8 Influences of adhesive thickness $b^{\text {a }}$ on debond crack strain energy release rate.

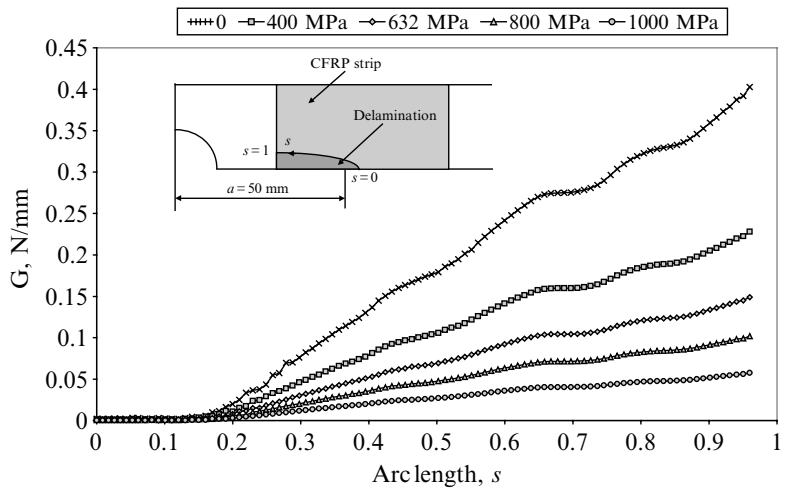

Fig. 9 Influences of pretension level $\sigma_{\mathrm{p}}$ on debond crack strain energy release rate. does not produce any variation of the stress intensity factor range in the steel plate but reduces the stress ratio and then promotes crack closure. ${ }^{18}$ This clearly shows the fundamental contribution of pretension to the effectiveness of the patch reinforcement of steel element.

Finally, the size of debonded region has a significant influence on the effectiveness of the crack reinforcement. On the basis of experimental findings, an elliptical debonded region with $c / b=1 / 5$ is assumed as reference value in the numerical analysis.

By increasing the debonded area the effectiveness of the crack reinforcement is decreased due to the reduction of the load transfer from the steel plate to the composite strips. A $78 \%$ reduction of $G$-values is then obtained by increasing the aspect ratio $c / b$ from $1 / 10$ to $1 / 2$ (Fig. 11). This means that the debonded area is expected to be limited to a region close to the steel plate crack (Fig. 12).

Note that a corresponding increment of the debonded area produced a $20 \%$ increment of the stress intensity factor in the steel plate. $^{6-11}$ Then the size of the debonded region has a significant influence on both the stress intensity factor levels in the cracked steel plate and then on the effectiveness of the repair.

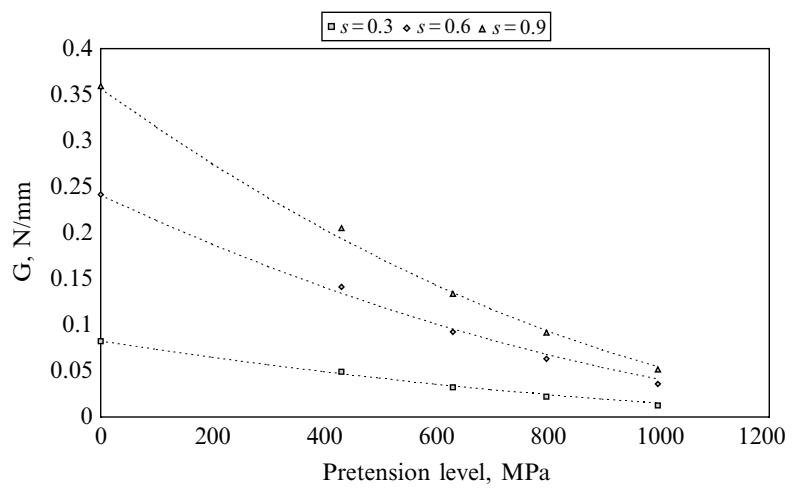

Fig. 10 Influence of the pretension level at different normalised arch lengths.

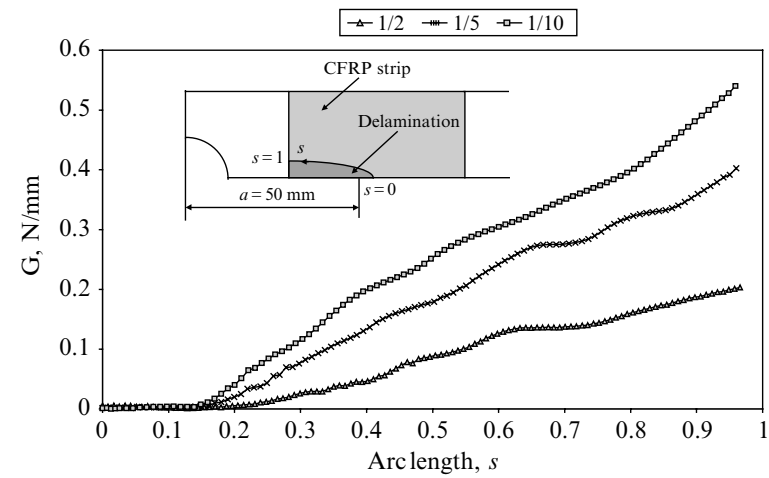

Fig. 11 Influences of the debond shape ratio $c / b$ on debond crack strain energy release rate. 


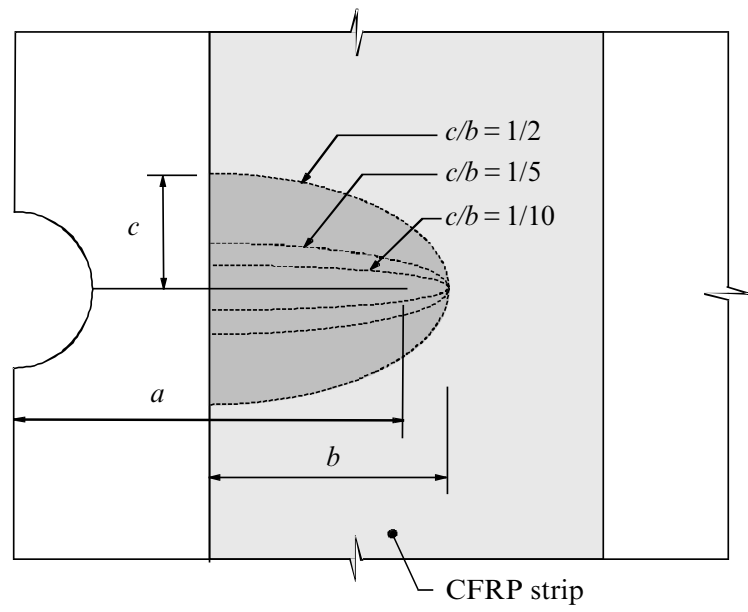

Fig. 12 Elliptical debond used in the parametric analysis.

\section{CONCLUSIONS}

Numerical analyses were performed with reference to experimental tests carried out in order to evaluate debond crack strain energy release rate, $G$, and to investigate the influence of some design parameters on the $G$ distribution. The three-layer technique is adopted in connection with the MVCCT to reduce the computational effort.

The crack growth induced delamination is limited to a region close to the steel plate crack for the steel elements under investigation reinforced by prestressed composite strips. This is due to the high stiffness of the steel plate, compared to that of the composite strip, that produces low debond strain energy release rate values at the debond front. Anyway, it can be concluded that the size of debonded region must be taken into account because it has a significant influence on the stress intensity factor level in the cracked steel plate.

Adhesive layer shear deformation due to adhesive thickness increment produces a major reduction of the $G$-values on the debond front. Note that a corresponding moderate increment of the stress intensity factors in the steel plates is achieved. Therefore it can be concluded that a thin adhesive layer produces a larger debonded area, which in return reduces the effectiveness of the reinforcement.

The application of a pretension to the composite strips prior to bonding produces a significant decrement of the $G$-values distribution along the debond front. Note that a corresponding major reduction of the stress ratio in the steel plate is achieved that promotes crack closure. Therefore, it can be concluded that pretension of the composite strips prior to bonding is strongly recommended in order to maximise the effectiveness of the bonded patch on the steel section.

\section{Acknowledgement}

The financial support to the first author by the Italian Ministry of Instruction, University and Research (MIUR) and to the second and third authors by the Swiss National Science Foundation and EPFL Lausanne is gratefully acknowledged. Thanks are also expressed to Sika AG - Zürich for supplying composite materials and to $\mathrm{Mr}$ Paolo Barichello for the computational help.

\section{REFERENCES}

1 Baker, A. A. and Jones, R. (1988) Bonded Repair of Aircraft Structures, Martinus-Nijhoff Publishers.

2 Umamaheswar, T. V. R. S. and Singh, R. (1999) Modelling of patch repair to a thin cracked sheet. Engng. Fract. Mech. 62, 267-289.

3 Meier, U. (1992) Carbon fibre-reinforced polymers: Modern materials in bridge engineering. Struct. Engng. Int. 1(92), 7-12.

4 Deuring, M. (1993) Verstärken von Stahlbeton mit Gespannten Faserverbund-Werkstoffen (in German), Report 224, Swiss Federal Laboratories for Materials Testing and Research, EMPA.

5 Ammar, N. (1996) Rehabilitation of Steel Bridge Girders with Graphite Pultrasion, CCM Report 96-26, Center for Composite Materials, University of Delaware.

6 Bassetti, A., Nussbaumer, A. and Hirt, A. Crack repair and fatigue life extension of riveted bridge members using composite materials. In: Bridge Engineering Conference (IABSE), 26-30 March, 2000, Vol. 1, Sharm El-Sheikh, Egypt, pp. 227-238.

7 Bassetti, A., Colombi, P. and Nussbaumer, A. Finite element analysis of steel members repaired by prestressed composite patch. In: Proceedings IGF2000, 3-5 May, 2000, CD-ROM, Bari, Italy.

8 Bassetti, A., Nussbaumer, A. and Hirt, A. Fatigue life extension of riveted bridge members using prestressed carbon fibre composites. In: Steel structures of the 2000s, 11-13 September, 2000, ECCS, Istanbul, pp. 375-380.

9 Bassetti, A., Nussbaumer, A. and Colombi, P. Repair of riveted bridge members damaged by fatigue using CFRP materials. In: Advanced FRP Materials for Civil Structures, 19 October, 2000, Bologna, Italy, pp. 33-42.

10 Bassetti, A. (2001) Lamelles Precontraintes en fibres de Carbone Pour le Reinforcement de Ponts Rivetes Endommages par Fatigue (in French), PhD Thesis n. 2440, Swiss Federal Institute of Technology, EPFL.

11 Bassetti, A., Facchini, M. and Jacquot, P. Ameliorament de la Tenue en Fatigue de Structures Metalliques: Evaluation Par Interferometrie Speckle Du Procede de Renforcement Par Lamelles Composites (in French), Photomecanique 2001, 24-26 April 2001, Poiters, pp. 351-358.

12 Sun, C. T., Klug, J. and Arendt, C. (1996) Analysis of cracked aluminium plates repaired with bonded composite patches. AIAA 7. 54, 369-374.

13 Naboulsi, S. and Mall, S. (1996) Modelling of a cracked metallic structure with bonded composite patch using the three layer technique. Comp. Struct. 35, 295-308.

14 Sun, C. T. and Jih, C. J. (1987) On strain energy release rates for interfacial cracks in bi-material media. Engng. Fract. Mech. 28, 13-20. 
15 Rybicki, E. F. and Kanninen, M. F. (1977) A finite element calculation of stress intensity factors by a modified crack closure integral. Engng. Fract. Mech. 9, 931-938.

16 Sun, C. T. and Qian, W. (1997) The use of finite extension strain energy release rates in fracture of interfacial cracks. Int. F. Solids Struct. 34, 2595-2609.

17 Mulville, D. R. and Mast, P. W. (1976) Strain energy release rate for interfacial cracks between dissimilar media. Engng. Fract. Mech. 8 555-565.

18 Suresh, S. (1991) Fatigue of Materials, Cambridge University Press, Cambridge.
19 Cloud, G. (1995) Optical Methods in Engineering Analysis, Cambridge University Press, Cambridge.

20 Ratwani, M. M. (1979) Analysis of cracked adhesively bonded laminated structures. AIAA F. 17, 988-994.

21 Zheng, S. and Sun, C. T. (1995) A double-plate finite-element model for the impact-induced delamination problem. Comp. Sci. Technol. 53, 111-118.

22 Barichello, P. (2001) Analisi di Elementi Metallici con Rinforzi in Fibra di Carbonio (in Italian), Master Thesis, Technical University of Milan. 